\title{
Positional Atrial Flutter?
}

\author{
Ali Usmani, MD ${ }^{1}$ \\ Aman Ali, $\mathrm{MD}^{2}$ \\ Saira Noor, MD ${ }^{1}$ \\ Anitha Rajamanickam, mo ${ }^{1}$
}

${ }^{1}$ Department of Hospital Medicine, Cleveland Clinic, Cleveland, Ohio.
${ }^{2}$ Department of Medicine, Lennox Hill Hospital, New York, New York.

Disclosure: Nothing to report.

A
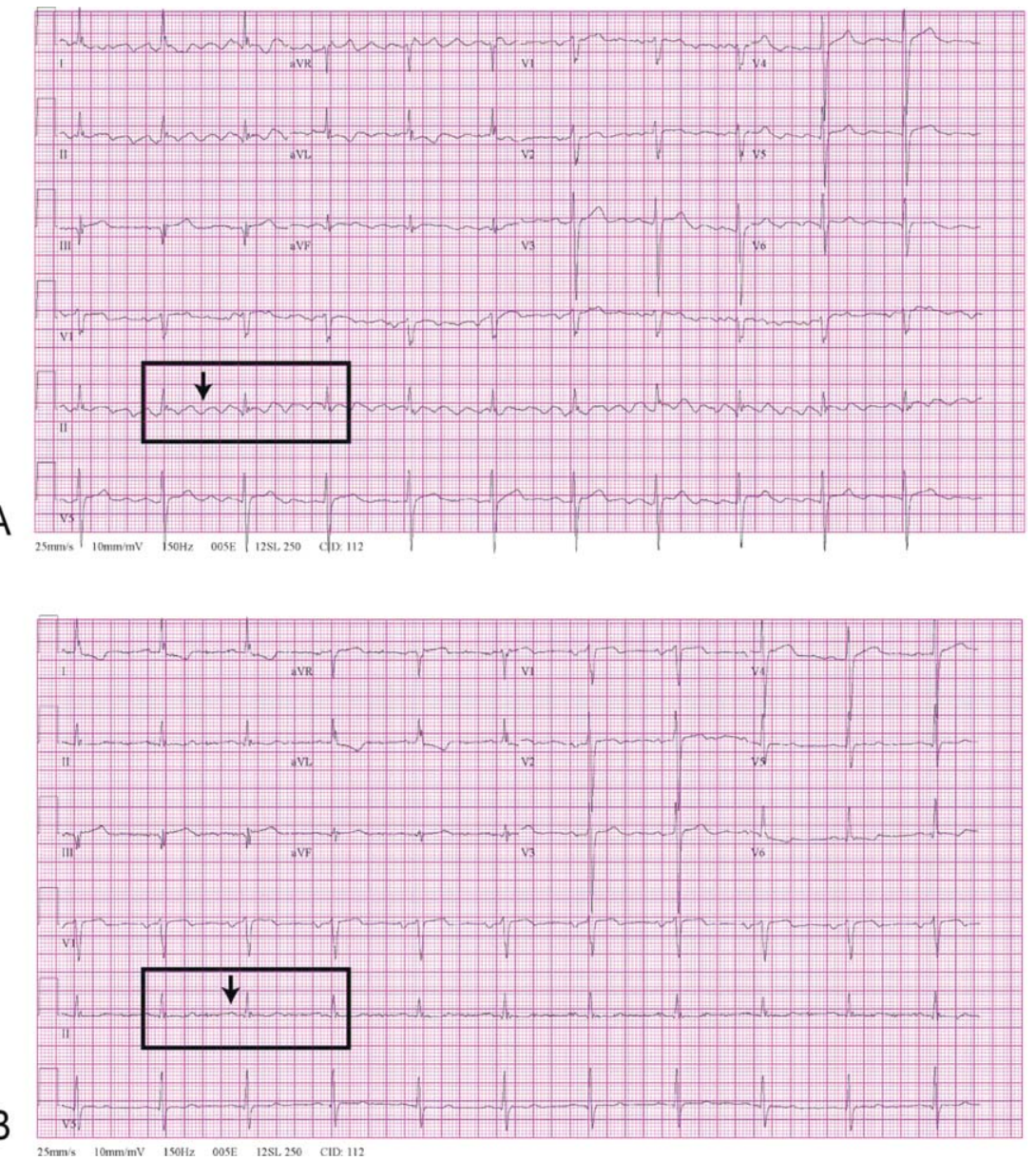

FIGURE 1. (A) Patient's original electrocardiogram (ECG) with "flutter waves.” (B) ECG with patient's hand being held.

A 68-year-old man with a history of congestive heart failure and hypertension presented to the emergency department with fatigue and dyspnea of 3 weeks duration. Physical examination was consistent with heart failure. In addition, a right upper extremity resting tremor was noticed. An electrocardiogram (ECG) revealed an "atrial flutter" with a conduction ratio of 4:1 (Figure 1A). He denied palpitations or a previous history of atrial flutter/fibrillation. Unlike typical atrial flutter, these "flutter like waves" were distinctly absent in lead III, the only limb lead not connected to the right arm.

While holding the patient's right arm to control the tremor, a second ECG tracing was obtained. As expected the "flutter like waves" disappeared (Figure 1B). These ECG findings were attributed to the patient's tremor. A neurological consultation established a clinical diagnosis of Parkinson's disease. His congestive heart failure (CHF) was treated with increasing diuretics and appropriate treatment for Parkinson's disease was initiated.

\section{Address for correspondence and reprint requests:}

Ali Usmani, MD, Cleveland Clinic, S-70, Department of Hospital

Medicine, 9500, Euclid Avenue, Cleveland 44195; Telephone: 216

445 8383; Fax: 216445 6420; E-mail: draliusmani@yahoo.com 